Recibido: septiembre de 2016

Aprobado: octubre de 2016

\title{
LA OCUPACIÓN DEL TERRITORIO Y SUS TRANSFORMACIONES EN EL PROCESO DE URBANIZACIÓN DEL SECTOR DE CAÑAVERAL, MUNICIPIO DE FLORIDABLANCA, SANTANDER*
}

DOI:

http://dx.doi.org//0.15332/rev.m.v13i0.1996

\author{
Fernando Estévez Suárez** - Universidad Santo Tomás, Colombia
}

Transformación urbana del sector de Cañaveral en inmediaciones de la Autopista Bucaramanga Floridablanca, 1968 - 2016

Fuente: Imagen izquierda, de Carlos Eslava; imagen derecha, de https://www.google.com.co/maps, ambas editadas por el autor (2016)
* Trabajo de investigación adscrito a la línea de Investigación en Planificación y Gestión del Territorio del Grupo de Investigaciones de la Facultad de Arquitectura de la Universidad Santo Tomás Seccional Bucaramanga (GINVEARQUI). Líder de línea: Carlos Humberto Gómez Arciniegas, arquitecto por la Universidad Santo Tomás Seccional Bucaramanga, MSc Lancaster University (Reino Unido) PhD Politécnico di Milano (Italia). Correo electrónico: carlos.gomez@ustabuca.edu.co

* Arquitecto, especialista en Aplicación de Metodologías en los Procesos Catastrales (IGAC); candidato a magíster en Ordenamiento Territorial y docente de la Universidad Santo Tomás. Correo electrónico: fernando. estevez@ustabuca.edu.co

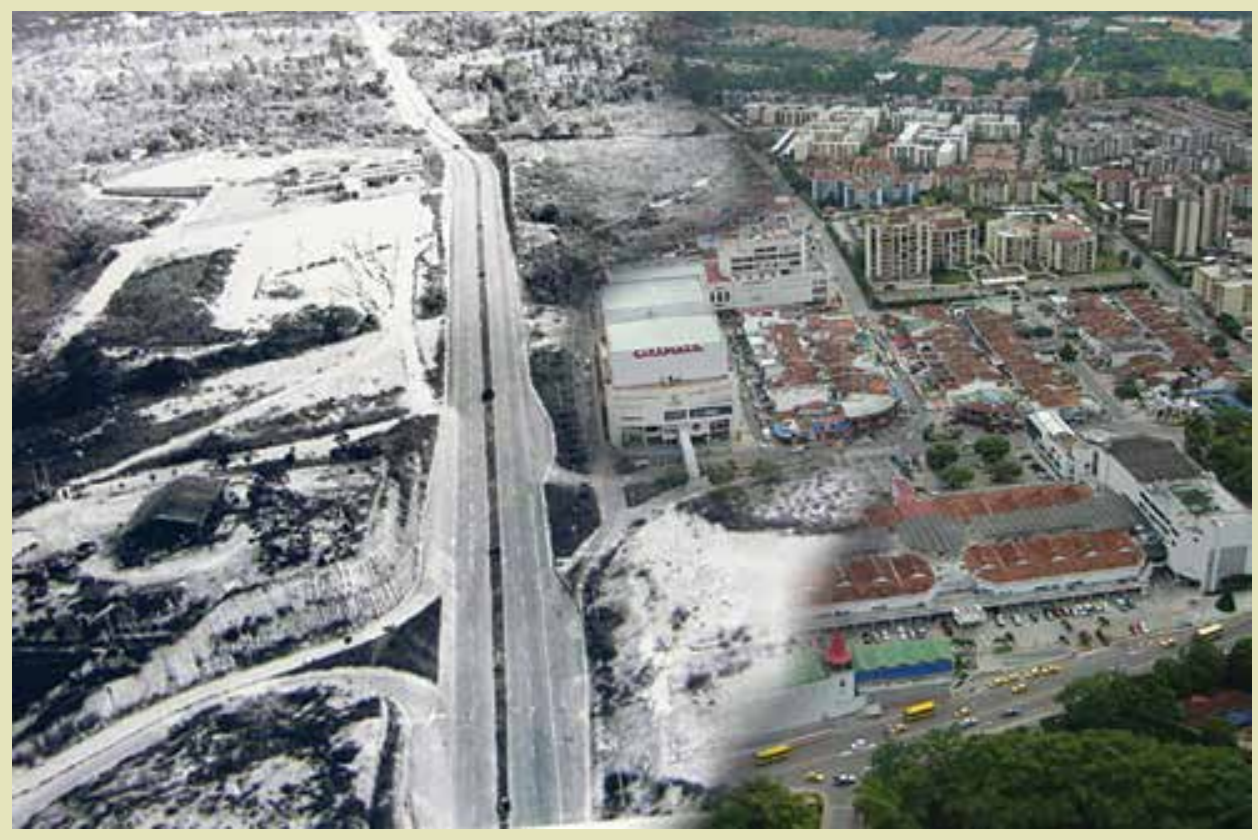

\section{RESUMEN}

El desarrollo de las ciudades colombianas se ha caracterizado principalmente por dinámicas de índole económica y social, que a su vez han generado una serie de trasformaciones físicas, actualmente evidentes en muchos puntos del tejido urbano. Este artículo presenta un análisis preliminar de las transformaciones urbanas que han sido identificadas en el sector de Cañaveral, generadas principalmente por el desarrollo económico de la zona. Dicho sector, perteneciente al municipio de Floridablanca, Santander, es uno de los componentes del área metropolitana de Bucaramanga y fue proyectado hace más de 40 años para uso residencial.

Para realizar el análisis se toma la información recopilada a partir de las visitas de campo, así como de un estudio cronológico de documentos públicos y fotografías que permiten organizar cronológicamente los procesos de transformación del territorio. Así bien, el artículo testimonia la aparición de nuevas redes de infraestructura y objetos arquitectónicos enfocados al desarrollo económico de un sector, pero que, por su falta de proyección, generaron impactos negativos que afectaron la calidad de vida de sus habitantes.

\section{PALABRAS CLAVE}

Desarrollo económico, transformaciones urbanas, usos del suelo, vivienda, centro comercial. 


\section{THE TERRITORIAL OCCUPATION AND ITS TRANSFORMATIONS IN THE DEVELOPMENT PROCESS OF CAÑAVERAL SECTOR AT THE MUNICIPALITY OF FLORIDABLANCA, SANTANDER}

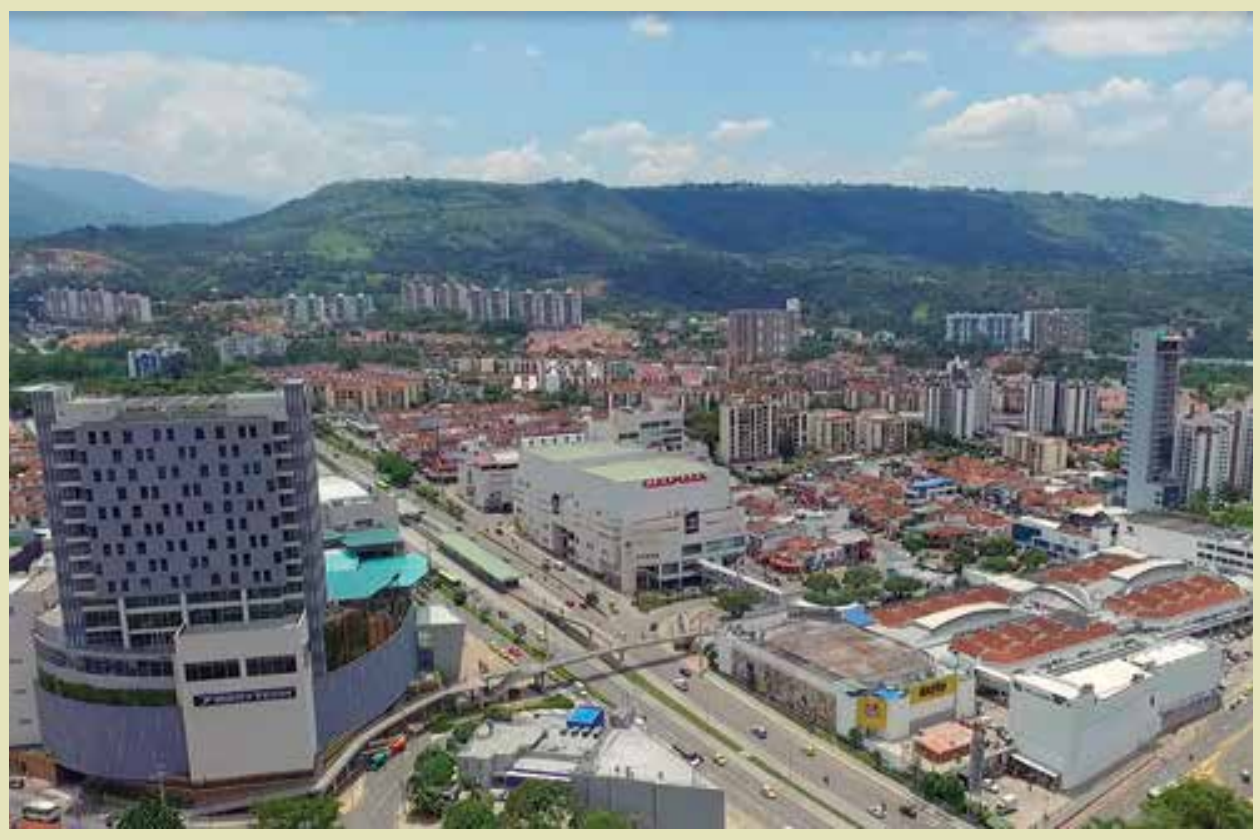

Panorámica del sector de Cañaveral, municipio de Floridablanca

Fuente: Imagen de https://www.google.com.co/ maps (2016).

\begin{abstract}
The development of Colombian cities has mainly been characterized by economic and social dynamics that in turn have generated several physical transformations, nowadays evident in many areas of the urban fabric. This article presents a preliminary analysis of the urban transformations that have been identified in the Cañaveral sector, mainly generated by the economic development of the area. This sector which belongs to the municipality of Floridablanca, Santander, is one of the components of the Metropolitan Area of Bucaramanga and was designed more than 40 years ago for residential use. To conduct the analysis, information gathered from the field visits as well as a chronological study of public documents and photographs serve as a starting point, allowing a chronological organization of the land transformation processes. Thus, the article testifies the emergence of new infrastructure networks and architectural objects focused on the economic development of a sector but, due to its lack of projection, generated negative impacts that affected the quality of life of their inhabitants.
\end{abstract}

\section{KEYWORDS}

Economic development, urban transformations, land uses, housing, shopping centre. 


\section{INTRODUCCIÓN}

En el presente artículo se hace un análisis a partir de las transformaciones urbanas generadas por la dinámica económica del sector de Cañaveral en el municipio de Floridablanca, las cuales derivan de la progresiva influencia del desarrollo comercial ligado a la generación de riqueza y crecimiento económico, pero que paradójicamente provocan un desplazamiento de la población local a causa de los cambios generados en el uso del suelo. Se trata entonces de un "desarrollo económico corrosivo", que afecta sectores específicos de una ciudad, destinados inicialmente a ser receptáculos de una actividad residencial normalmente ligada a cualquier proceso de desarrollo urbano, donde se incorporan los debidos usos complementarios, como elementos indivisibles para el crecimiento y desarrollo de la ciudad. Un claro ejemplo de ello es el caso de la ciudad de Bucaramanga, capital del departamento de Santander, declarada según el Banco Mundial (2015) en su estudio de "Ciudades competitivas para estudios y crecimientos", como la ciudad más próspera de América Latina y ejemplo para el mundo. Según el Departamento Administrativo Nacional de Estadística - DANE (2016) Bucaramanga cuenta con 521.857 habitantes y junto con Floridablanca, Girón y Piedecuesta conforman el área metropolitana con un total de I.I 32.339 habitantes, siendo la quinta aglomeración urbana más poblada del país.

Así bien, el municipio donde se realiza el estudio es Floridablanca, según lo mencionado anteriormente, uno de los municipios que conforman el área metropolitana de Bucaramanga - AMB. Este cuenta con una extensión aproximada de $97 \mathrm{~km}^{2}$ y se encuentra conurbado por el norte con la ciudad de Bucaramanga. El municipio de Floridablanca es además conocido por sus centros comerciales, sus clínicas de alto nivel y su creciente desarrollo urbanístico, acorde con las necesidades del área metropolitana, el cual trajo consigo la aparición de diferentes áreas residenciales y un notable incremento del sector terciario durante las tres últimas décadas; situación verificable en el caso del barrio Cañaveral, si se tiene en cuenta que para sus inicios se proyectó en 1982 el Centro Comercial Cañaveral, el cual sería inaugurado en 1989. Este hecho marca el inicio de una fuerte actividad comercial en el área, hoy en día más que evidente, ya que cuenta con cuatro centros comerciales que desde su aparición han generado controversias y opiniones divididas, relacionadas con un impacto urbano a gran escala y un "deterioro silencioso" del sector, debido a algunas inconsistencias o vacíos en los procesos de planificación urbana que se revierten negativamente en la calidad de vida de los habitantes y el deterioro del paisaje urbano.

De hecho, el sector evidencia una fuerte ocupación del suelo a causa de la aparición de objetos arquitectónicos que han llegado a saturar el sector visualmente y a generar, en términos de densificación, un impacto social, urbano y ambiental de considerables magnitudes. El resultado es preocupante, pues la actividad comercial ha traído consigo el aumento del déficit de espacio público, carencia de zonas verdes y una movilidad caótica que a su vez han propiciado el desplazamiento de la actividad residencial, transformándose e incumpliéndose de esta forma un orden prestablecido en la proyección del sector realizada hace más de 40 años. Por tanto, el presente texto se fundamenta en un análisis cronológico de las transformaciones del sector de Cañaveral que incluye la forma en cómo se proyectó inicialmente y cómo este fue cambiando a lo largo del tiempo, evidenciando las principales dinámicas y transformaciones que han causado el denominado "caos urbano".

En términos metodológicos, para la realización de este documento se acude a la recopilación de la información histórica disponible, apoyándose en fuentes de información primaria y secundaria, con el fin de caracterizar el proceso de urbanización. Asimismo, se busca clarificar las transformaciones y las dinámicas generadoras en este proceso de expansión urbana y proyección territorial, a través de un análisis comparativo de los documentos analizados y las evidencias recolectadas. 
En consecuencia, el documento se divide en cuatro secciones. La primera explora los orígenes de esta expansión urbana, el proceso de ocupación del sector de Cañaveral desde sus inicios al día de hoy y el modelo estructurante propuesto para este desarrollo. La segunda expone las dinámicas y transformaciones en el ordenamiento territorial, a partir del estudio de caso del sector de Cañaveral. La tercera analiza espacialmente el sector e individualiza las afectaciones urbanas que se están dando en el lugar. Por último, se presentan algunas conclusiones que bien pueden funcionar como punto de partida para futuras reflexiones o procesos de investigación relacionados con el tema.

\section{CONTEXTUALIZACIÓN HISTÓRICA DEL SECTOR DE CAÑAVERAL}

El área metropolitana de Bucaramanga cuenta con 4 municipios que la conforman, Bucaramanga, Floridablanca, Piedecuesta y Girón. Esta fue creada mediante ordenanza 20 del I5 de diciembre de 198I, por la Asamblea de Santander, con la cual se ponía en funcionamiento con la participación inicial de 3 municipios, donde Bucaramanga funcionaba como gran centro urbano o núcleo principal y los municipios de Floridablanca y Girón como localidades contiguas. Para el año 1984 se expidió la Ordenanza 48 en la cual se autorizó la entrada del municipio de Piedecuesta al área metropolitana de Bucaramanga, lo cual se formalizó mediante el Decreto 332 del 2 de marzo de 1985.

Ahora bien, el desarrollo urbano de Bucaramanga por fuera de lo que se denomina la meseta, se inició a mediados de los años 60 con Floridablanca y la construcción de la autopista. Solo dos carriles en cada uno de los sentidos sin senderos ni espacio peatonal, demostraba la poca inversión en la zona, ya que para esa época la meseta de Bucaramanga tenía un reducido espacio de desarrollo urbanístico y la opción más viable estaba al sur del área metropolitana, aunque la autopista a Floridablanca ya había sido construida en 1968, era difícil construir o proyectar a falta de un interconector que en este caso fue el viaducto García Cadena. El empresario urbanizador Dr. Armando Puyana, con su empresa constructora Urbanas estaba planeando Cañaveral, que estaría en un punto equidistante entre Floridablanca, Bucaramanga, Girón y Piedecuesta; así cuando se pone en servicio el mencionado viaducto comienza a hacerse realidad la etapa de urbanización de esta zona.

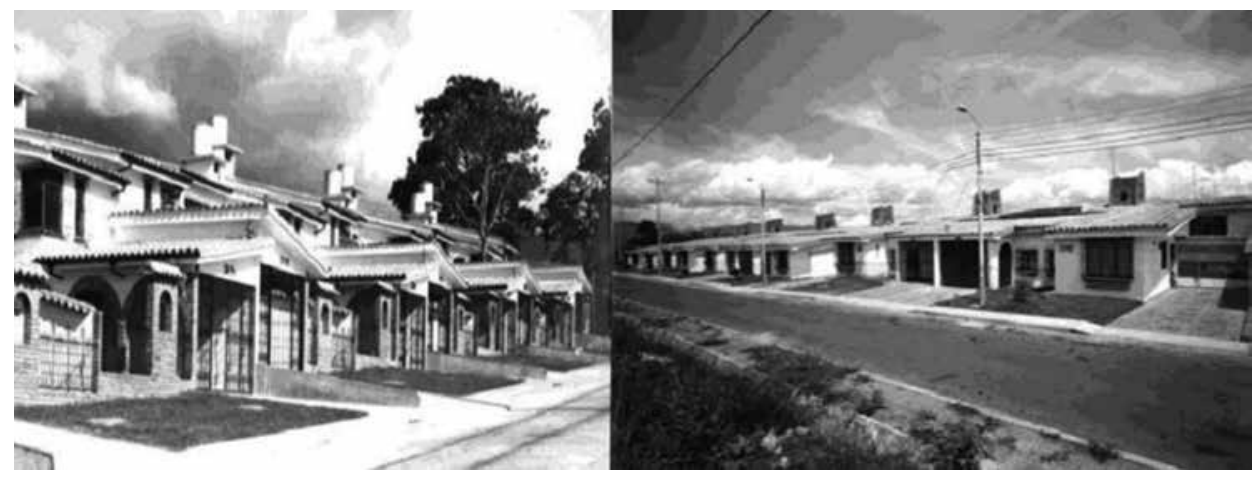

Es así, como el barrio Cañaveral inicia su construcción en la década de los años setenta. Las primeras ventas se realizan a mediados de 1972 con los programas de casas unifamiliares tipo A, B, C, D, E y F y los conjuntos residenciales "Hoyo en Uno" y "La Pera”, los cuales presentaban buenas especificaciones técnicas y constructivas y elementos de arquitectura colonial. Así comienza a poblarse este sector y expandirse el territorio hacia el costado occidental de la Autopista Bucaramanga - Floridablanca (Rodríguez, Lozada, 2012, p. 39).
Figura I. Cañaveral 1965. Viviendas tipo del sector

Fuente: Archivo personal del Dr. Néstor Rueda Gómez. Cortesía de Urbanas S.A. 
Figura 2. Primeras ocupaciones en el sector de Cañaveral, Floridablanca

Fuente: Fotografía original de Carlos Eslava y editada por el autor (2016).
En la figura 2 se observa la autopista Bucaramanga - Floridablanca, así como el loteo del sector de Cañaveral para vivienda en color amarillo, y la construcción de algunas casas de la zona proyectadas netamente para vivienda que se ven influenciadas con la idea de Lluís Sert de "Unidades Vecinales", que aparece como modelo en el desarrollo habitacional, y se ve aplicado en el sector de Cañaveral.

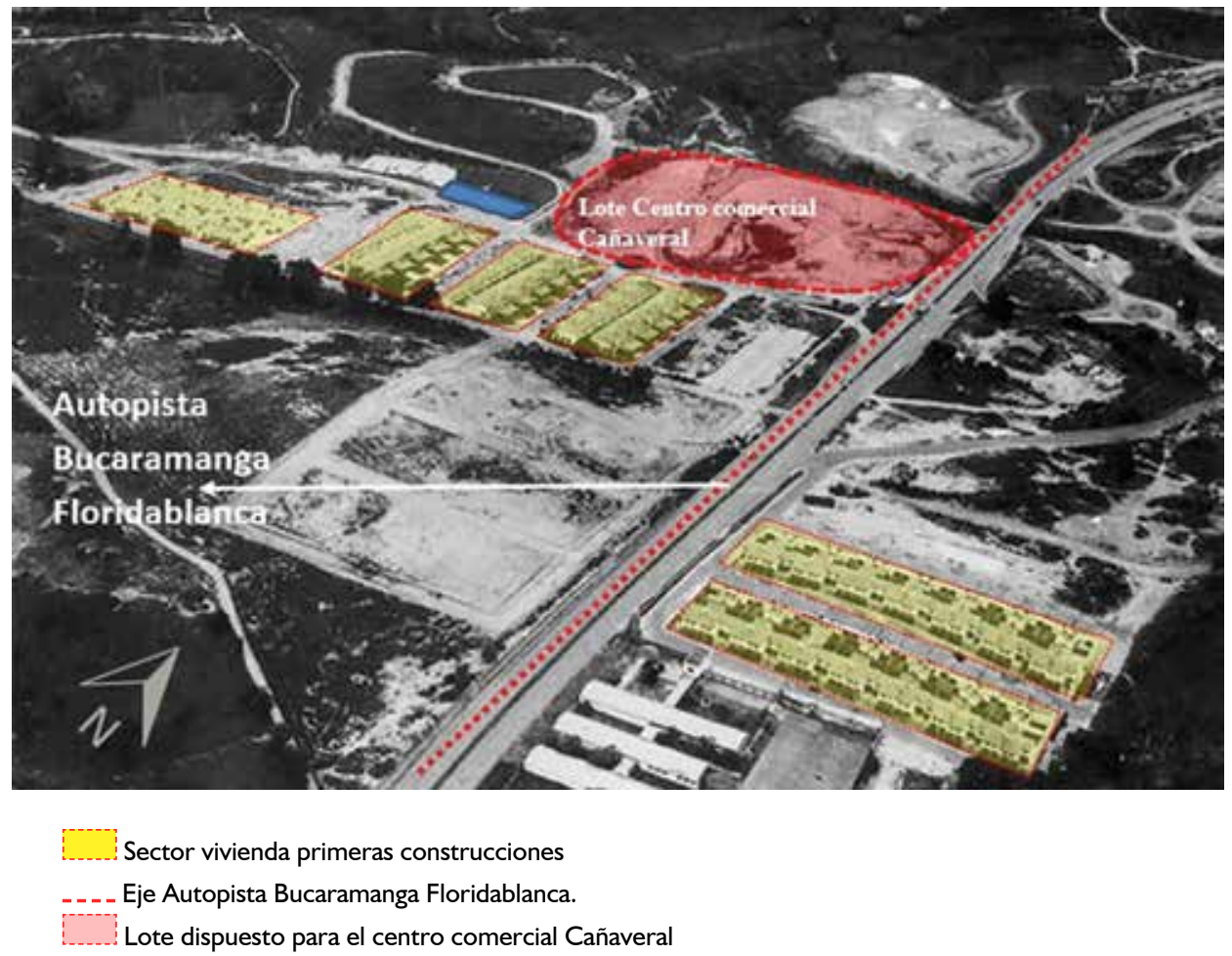

Este tema fue tratado en el V CIAM (1937) y desarrollado en un libro de 15 capítulos centrados en las cuatro funciones del urbanismo: vivienda, trabajo, ocio y circulación, donde se definía la unidad vecinal como un conjunto formado por grupos de vivienda y servicios comunitarios, que estaban rodeados de espacio y de otros elementos que eran capaces de conducir a mejorar la habitabilidad. Respecto a ello, Sert afirmaba que "una célula de vivienda no estará completa sin unos servicios comunitarios que amplíen sus funciones" (I942). La unidad vecinal (UV) representaba para Sert la primera unidad básica de planeamiento, la unidad más pequeña que compone la ciudad a modo de módulo repetitivo, constituida por el número de viviendas necesarias para alojar una cantidad suficiente de personas capaces de aprovechar los servicios de una escuela elemental y que habitarán con una mejor calidad de vida. De los años 1942 a 1959 junto con Paul Lester Wiener, como socios de la firma Town Planning Associates realizaron planes urbanísticos para ciudades latinoamericanas en Brasil, Perú, Venezuela, Cuba y Colombia (Schnitter, 2003).

La organización formal de la UV se determinaba por un área con calles de servicio secundario, donde ninguna calle directa rompía la unidad, y contemplaba casas unifamiliares adosadas, edificios de cuatro pisos o en altura con ascensor y unos servicios comunales básicos. Ahora bien, ya para el año 1977 el sector de Cañaveral se estaba proyectando a partir del modelo de UV, dentro del cual se había analizado la viabilidad de construir el Centro Comercial Cañaveral, según se evidenció en documentación y archivos históricos de la constructora Urbanas. Dicho centro comercial se construyó en 1983 y contribuiría al abastecimiento comercial y de entretenimiento de la zona con mayor desarrollo de la 
ciudad. Esta área fue denominada como área de expansión, y su proyección inicial se basaba en el desarrollo de vivienda con una mejor calidad de vida, con servicios complementarios y dotacionales. Para la década de los ochenta el sector de Cañaveral era en su mayor parte residencial, donde la altura máxima no superaba los 2 pisos. Ya para la década de los noventa se empiezan a consolidar otros servicios dotacionales como el hospitalario, así como otros usos complementarios a mayor escala, que llegarán a superar la cobertura zonal y pasaran a prestar servicios a nivel metropolitano.

Durante este proceso de desarrollo, el sector va a evidenciar una urbanización del $80 \%$, ya para inicios de la década del 2000 , coincidiendo con lo que en este artículo se ha denominado la llegada del capitalismo, viéndose reflejado en la aparición de nuevos objetos arquitectónicos que para muchos brindarían la posibilidad de generar más desarrollo económico y comercial, desconociendo hasta cierto punto las implicaciones de cambio de uso del sector, pasando de un componente residencial fuerte a uno comercial que poco a poco desplazaría a las personas sobre otras áreas del mismo.

Frente a esto, después de algunos años de ser una zona tranquila y residencial, aparecen tres objetos arquitectónicos estratégicamente ubicados, el Centro Comercial La Florida que en el 2003 abrió la primera etapa, y en el 2004 abrió la segunda, que comprende dos torres, una torre que es centro empresarial y cuenta con 39 oficinas, zona de comidas, y el almacén ancla Jumbo, llamado anteriormente Mercadefam, y una segunda torre con locales comerciales. Estas dos torres fueron construidas en un área de 2 manzanas unidas por 2 puentes peatonales para facilitar el flujo de personas y las actividades comerciales, y un puente vehicular único en América Latina. Por su parte, el Centro Comercial Caracolí abrió sus puertas en el 2013, generando un gran impacto social, económico y urbano en el sector.

Es evidente que con la aparición del primer centro comercial en la zona, se generó un desarrollo económico notable, aunque el comercio local se desplazó y empezó a ubicarse en sus alrededores, estableciendo diferentes tipos de negocios, como restaurantes, supermercados, centros educativos, centros médicos, papelerías, centros odontológicos y estéticos. Mientras esto ocurría, se empezaron a construir unidades habitacionales unifamiliares y condominios de 2 pisos, edificios de estrato alto que comprendían entre 5 y 22 pisos, desarrollados principalmente por las empresas constructoras más importantes, como Urbanas S.A, Marval S.A, Fénix Construcciones y HG.

Actualmente, muy pocas casas mantienen su uso y fachada original, evidenciando que por lo menos el $95 \%$ del sector ha pasado de vivienda a comercial o uso mixto, como puede apreciarse en la figura 3.
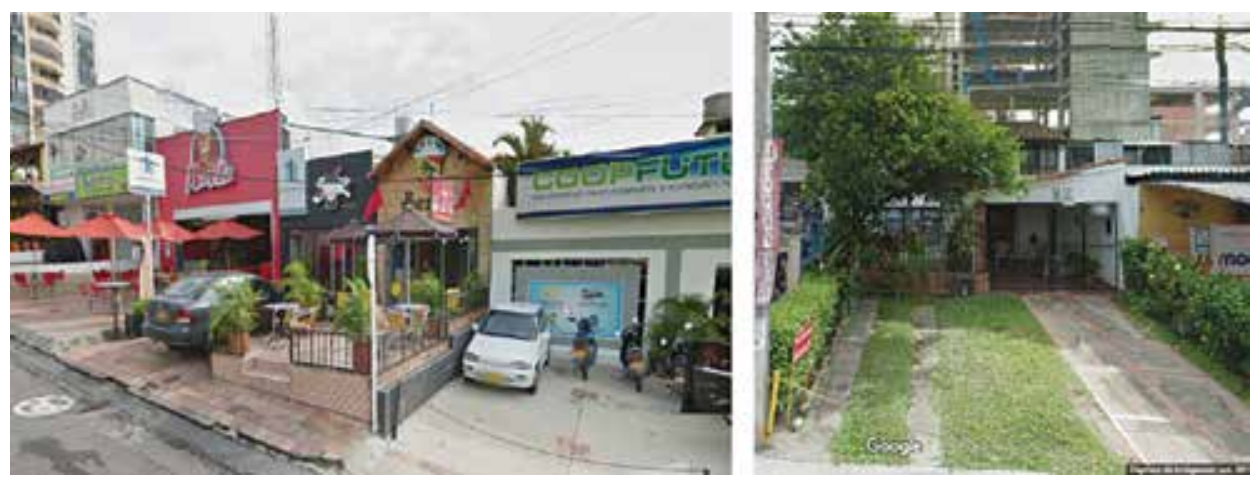

Figura 3. Locales comerciales (izquierda) y tipología de vivienda inicial en el sector de Cañaveral (derecha)

Fuente: Fotografias tomadas de https://www. google.com.co/maps (2016). 


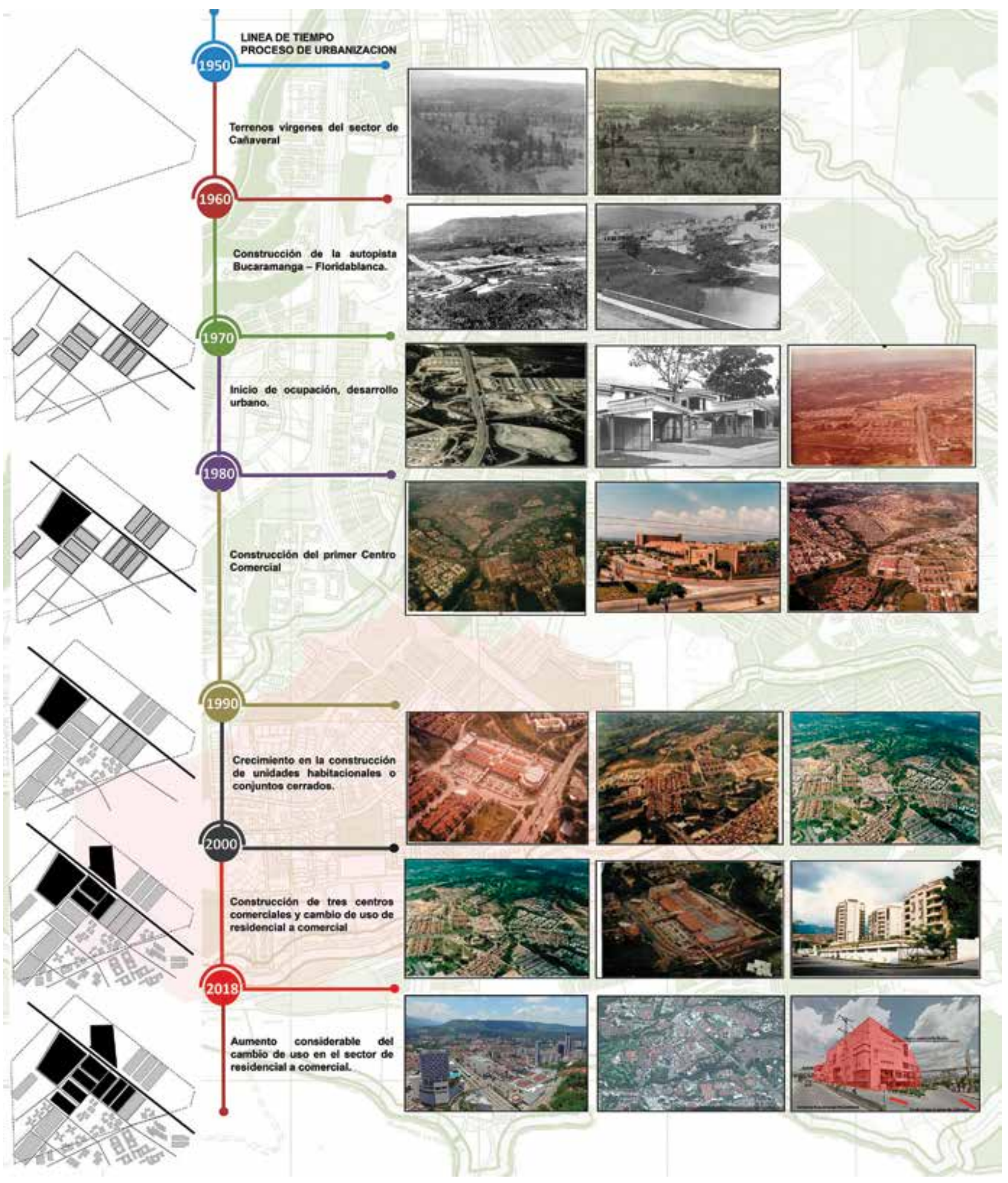

Figura 4. Línea de tiempo - Ocupación del sector de Cañaveral

Fuente: Diagrama elaborado por el autor a

partir de imágenes del fotógrafo Carlos Eslava

y del periódico Vanguardia Liberal. 


\section{DINÁMICAS Y TRANSFORMACIONES EN EL ORDENAMIENTO TERRITORIAL}

En el marco del proceso de proyección, expansión, urbanización y cambio de los municipios, se presenta una serie de dinámicas de diferentes tipos, que llevan a generar transformaciones, positivas o negativas, que afectan directamente al territorio, como por ejemplo las dinámicas sociales de carácter migratorio y demográfico, las cuales con una mala proyección del espacio intervenido pueden generar caos si no se tiene en cuenta el área de ocupación y de $\mathrm{km}^{2}$ por habitante, referentes al espacio público y los índices de ocupación.

Por otra parte, la dinámica de ocupación del suelo tiene que ver con temas de construcción, donde debe respetarse el uso al cual fue destinado o sectorizado, así como los índices de ocupación y construcción dispuestos en los instrumentos de gestión para no generar conflictos derivados de la relación de las altas densidades y el poco espacio para el desarrollo de las actividades de quienes habitan el sector, así como la protección de zonas naturales y reserva ecológica. En el caso de la dinámica económica, esta se refiere a temas de industria y comercio presentes en el territorio, que pueden generar desarrollo o crear incompatibilidades $y$ transformaciones de alto impacto.

Dichas transformaciones pueden obedecer a cambios de uso de suelo como se observa en la figura 5 , donde es evidente una deficiencia de espacio público por $\mathrm{km}^{2}$ en relación con los habitantes, lo cual a su vez genera deficiencia en el espacio correspondiente a la infraestructura vial, lo que lleva a la congestión vehicular. Otras transformaciones se refieren a la ausencia de zonas verdes en el sector por endurecimiento, relación no equilibrada en cuanto al comercio, la vivienda y los servicios complementarios.
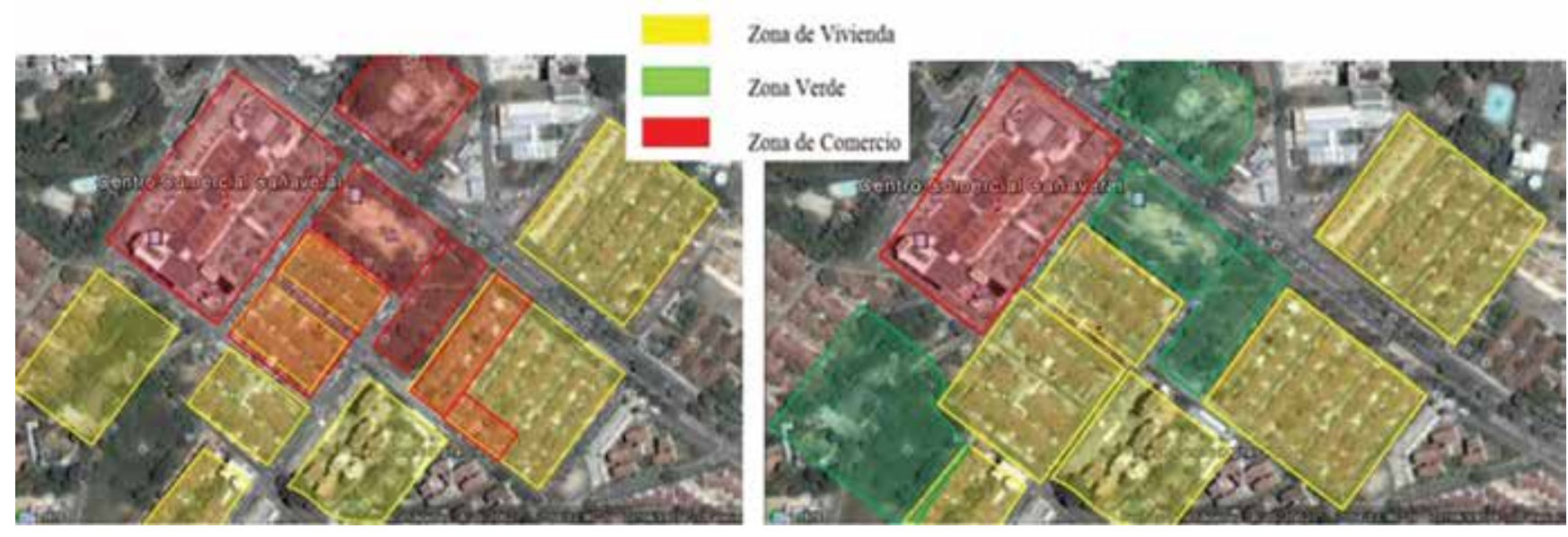

Ahora bien, actualmente se tiende a relacionar el cambio en las dinámicas mencionadas con determinados tipos de desarrollo, especialmente el crecimiento económico. Desde otras perspectivas se ha estimado la necesidad de que ese desarrollo contemple de manera determinante la articulación necesaria entre las dimensiones sociocultural, ambiental y política; pero realmente en ese proceso se ha generado una degradación de recursos ambientales en la mayoría de las zonas del territorio nacional (Hernández, 20I0, p. 103).
Figura 5. Cambios de usos y ocupación en el sector de Cañaveral (izq. sector en el 2016, der. sector en 1985)

Fuente: Imágenes tomadas de https://www. google.com.co/maps y editadas por el autor (2016). 


\section{Transformaciones del sector de Cañaveral por dinámicas sociales}

El ordenamiento u organización espacial de las dinámicas sociales, la interrelación con las funciones territoriales, los servicios y equipamientos, teniendo como base las características ecológicas del territorio, los patrones culturales de la población que lo habita y sus aspiraciones y sueños para vivir en este, se plantean como instrumentos para alcanzar unas mejores condiciones en la calidad de vida de las poblaciones $y$, por ende, como instrumento para construir "un orden deseado", que es diverso de acuerdo con los patrones culturales de las poblaciones y sus concepciones acerca del pasado, del presente y del futuro como sociedad (Hernández, 20l0, p. 4). Sin embargo, esto parece no haber tenido en cuenta al momento de controlar la expansión del sector de Cañaveral.

Dicho sector corresponde a los estratos 5 y 6 , una estratificación alta dentro de los estándares usados en la ciudad, teniendo en cuenta que el estrato I corresponde a viviendas de menor calidad constructiva, $y$ con habitabilidad poblacional de menores recursos económicos, y el estrato 6 al de mayor capacidad económica y mejor calidad en los estándares constructivos. Por otro lado, dentro del sector se ha evidenciado la incursión del comercio desmedido, la aparición de ventas ambulantes que obstruyen el espacio público, y la falta de zonas apropiadas para la recreación, teniendo en cuenta la alta densidad poblacional. De igual forma, los ruidos y el tráfico de automóviles generan conflicto y afectaciones de salud, mientras que la construcción de edificaciones ha modificado notablemente el paisaje, generando un deterioro en la calidad de vida al presentarse el fenómeno de tala y erradicación de zonas verdes. También, en el caso de las áreas donde se ubica el mayor número de locales comerciales, se presenta un alto índice de inseguridad después de las 9:00 p.m. cuando la actividad de la zona se detiene.

Por otro lado, los conjuntos cerrados del sector de Cañaveral no han tenido en cuenta la relación de espacio público por persona al momento de proyectar las unidades habitacionales. De igual forma, el valor del suelo generó un incremento en los índices de construcción, contribuyendo a aumentar los ingresos para las empresas privadas dedicadas a esta actividad, situación que se ha hecho tangible en toda Colombia, donde la planificación ha tenido un enfoque predominantemente económico (Borja, 1996) y, en esa perspectiva, el territorio, entendido como un sustrato diverso, no se ha concebido de manera integral, conjugando las diferencias regionales y la gran riqueza cultural y ecológica de cada lugar (Hernández, 20I0, p. 4).

Si se miran algunos ejemplos internacionales de cómo la globalización ha llevado a las ciudades al llamado desarrollo económico y tecnológico, en el caso de México estas se han convertido en el escenario improvisado de modelos y de políticas urbanas estratégicas insostenibles, que no han ocultado el crecimiento de la pobreza, la discriminación social, la delincuencia organizada o no, la vulnerabilidad social y, sobre todo, la incomunicación e insolidaridad (Sánchez, 20I2, p. 4I).

Para el caso de Francia, el ordenamiento territorial aparece como la necesidad de revisar la ocupación tradicional del espacio en relación con las necesidades de la vida moderna. Con el enorme crecimiento urbano en la segunda mitad del siglo $X X$ aparecen nuevos conceptos como los referentes a las áreas metropolitanas en los que se distinguen diversos elementos relacionados con el funcionamiento de la gran ciudad, conectados, incluso, con espacios alejados de los centros, pero dependientes de la ciudad. En la actualidad, estos esfuerzos por entender el espacio ocupado y organizado por el ser humano han permitido la creación de nuevos conceptos de ocupación del territorio que se expresan en términos de espacio urbano o rural, frente a una nueva escala de uso del suelo o de conflictos en la organización moderna del espacio. 


\section{Transformaciones del sector de Cañaveral por dinámicas económicas}

Como parte del desarrollo económico y el crecimiento habitacional del sector de Cañaveral, se construyen cuatro centros comerciales, generando una competencia fuerte por captar la atención de los usuarios. Dichos centros se ven enfrentados al comercio informal, así como a los pequeños comerciantes instalados en donde anteriormente era zona de uso exclusivo residencial.

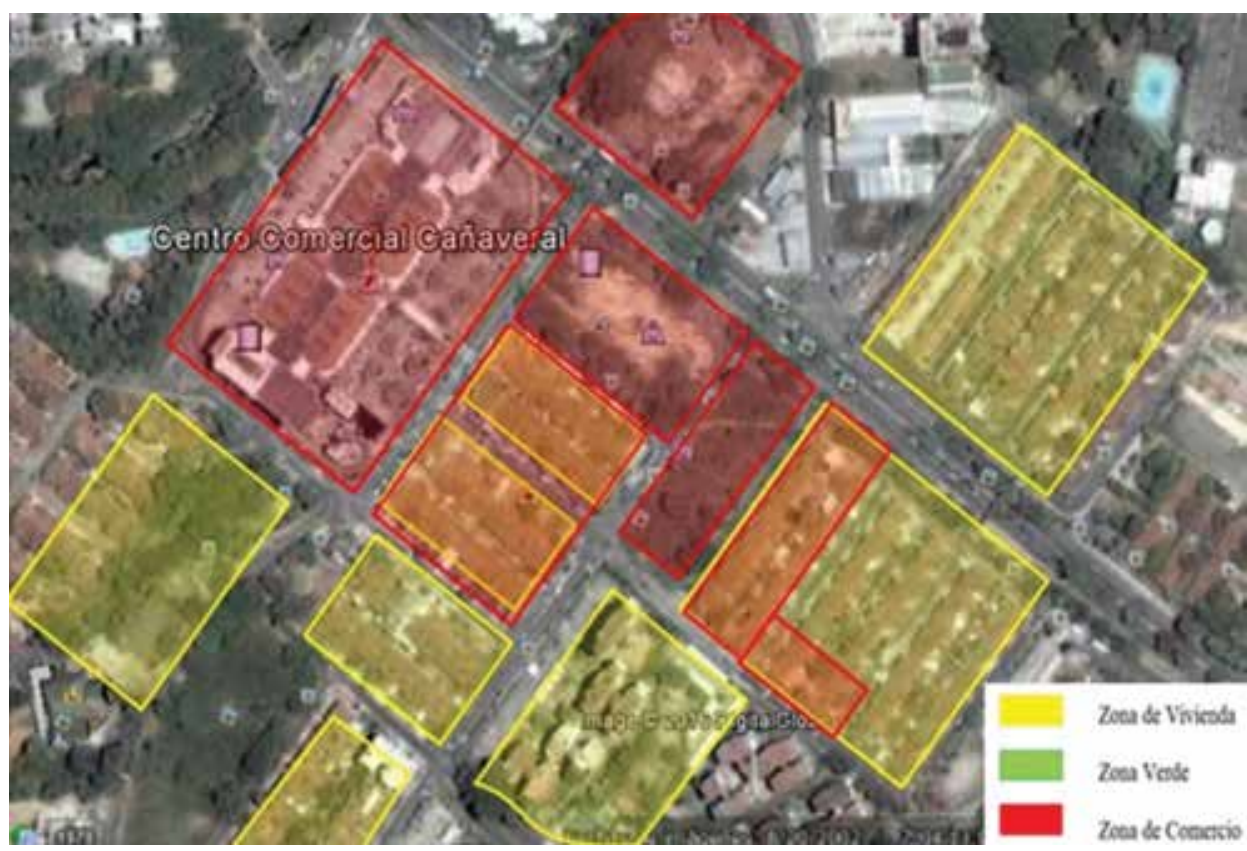

La situación anterior lleva a una saturación del comercio en la zona, ya que lo que anteriormente era vivienda se convirtió también en comercio, las vías o flujos vehiculares afectados por su proyección a corto plazo, el incremento de vivienda en altura que representa una densificación desmedida en un sector de estrato social alto. Si se hace el ejercicio comparativo cuando se empezó a consolidar el sector, 4 lotes correspondían a 4 familias, con un total de 18 personas y 8 vehículos aproximadamente en total. Actualmente, en los mismos 4 lotes hay un edificio de 4 apartamentos por piso, por 15 pisos en total que corresponde a 60 apartamentos, un aproximado de 120 vehículos en total y 270 personas residentes en esta unidad habitacional construida en altura.

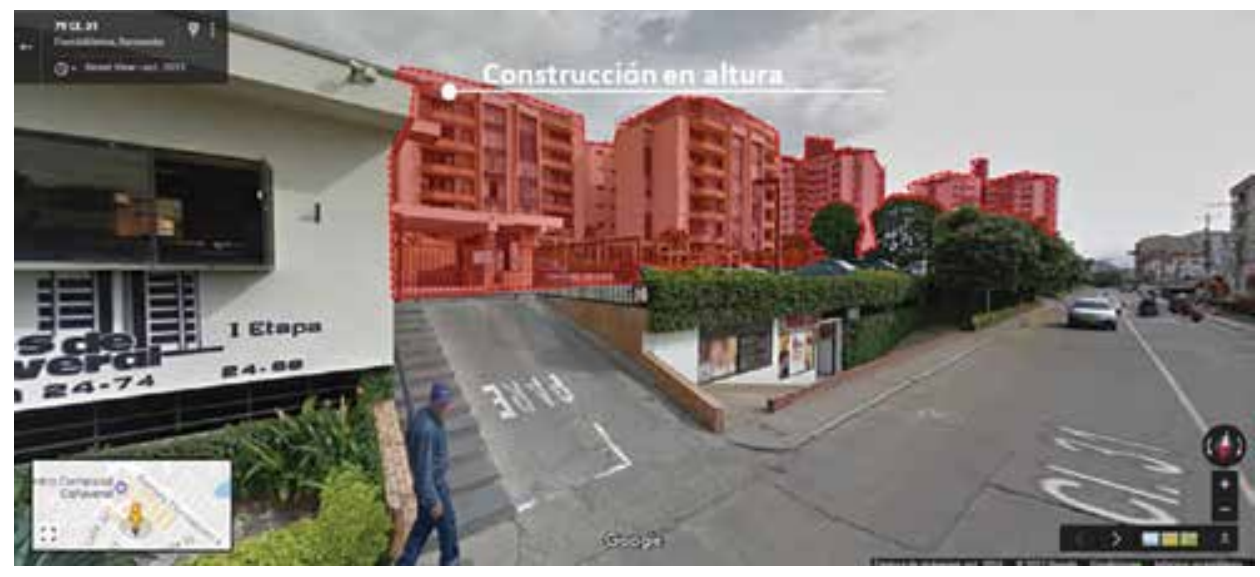

Figura 6. Cambio de uso del suelo en el sector de Cañaveral (de vivienda a comercio) Fuente: Imágenes tomadas de https://www. google.com.co/maps y editadas por el autor (2016)
Figura 7. Construcciones en altura en el sector de Cañaveral

Fuente: Imágenes tomadas de https://www. google.com.co/maps y editadas por el autor (2016) 
Ahora bien, si se tienen en cuenta los fundamentos teóricos sintetizados, se plantea que existe una relación entre segregación social y fragmentación urbana, la cual es posible evidenciar en determinada escala de observación. Es necesario mencionar que mientras la segregación social hace referencia directa a los espacios sociales, al comportamiento de los grupos, la fragmentación urbana se ocupa de la continuidad o el fraccionamiento de los espacios urbanos. La relación entre ambos fenómenos se estudia actualmente en función de constatar el papel de los centros comerciales en su generación o intensificación. Para ello se consideran ciertos factores, como los precios del suelo, la estratificación social y los precios de bienes y servicios (Palacios, 2015, p. 329). Por otra parte, y retomando el estudio de caso, en las figuras 8 y 9 se observa cómo las volumetrías pesadas de los centros comerciales generan un impacto de tipo visual saturando y afectando el paisaje en el acceso principal al sector de cañaveral.

En la figura 10 se observa claramente el desplazamiento por el cambio de uso de una zona de vivienda a una zona comercial, endurecimiento de las zonas verdes para ser adecuadas como espacio de comercio, el cambio de fachadas, en lo que anteriormente era vivienda, la contaminación visual por el uso de avisos publicitarios, el mínimo uso de las zonas verdes y la carencia de árboles en la zona; mientras que en la figura I I es evidente la sensación de pesadez del volumen del Centro Comercial La Florida, observándose un desequilibrio entre el índice de ocupación sobre el lote ocupado por este edificio y el espacio público. De igual forma, también se observa que en la manzana comprendida entre la Cra $26^{\mathrm{a}}$ y Cra 26 y calles 30 y 31 , se han generado cambios evidentes en su uso, así como saturación de las fachadas con avisos publicitarios y mixtura de materiales.

\section{BREVE ANÁLISIS URBANO - ESPACIAL DEL SECTOR DE CAÑAVERAL}

Se observa que toda intervención urbana debe regirse por tres aspectos importantes para tener en cuenta en cualquier proyección: las vías, seguido de los usos que van a ser distribuidos en el sector y el espacio público o zonas verdes. Teniendo en cuenta lo anterior, el sector de Cañaveral tiene una serie de problemas significativos generados por: aparición de cuatro centros comerciales y una zona residencial con altura de 2 pisos que se sobre densificó por la construcción de conjuntos cerrados con torres de más de 5 pisos, usos dispersos dotacionales y de servicios complementarios.

Según Di Gregorio analizando un punto de vista internacional il territorio, cioe uno spazio fisico di una certa ampiezza geografica, intersoggettivamente delimitato, contiene infatti tutte quelle organizzazioni che le persone hanno costruito per garantirsi una vita adeguata, specializzando ne i compiti e definendone i confini, in relazione alla crescita dellla loro stessa organizzazione sociale (2007).

Entendiéndose que el territorio es el espacio físico con unos límites determinados que posee organizaciones construidas por la gente para garantizar una calidad de vida adecuada y que especializa sus tareas definiendo los límites en la relación de su crecimiento y organización social. En el caso del sector estudiado, el incremento de la vivienda auspiciado por la densificación en altura aumenta notablemente la cantidad de personas residentes $y$, por ende, la cantidad de vehículos que transitan de propiedad de los residentes, sin descartar los visitantes que llegan a los 3 centros comerciales, aumentando la necesidad de espacios de esparcimiento o espacio público e infraestructura vial. Además se observa un cambio de uso en el que se desplazó la vivienda y se transformó en comercio de bajo impacto. Todo lo anterior es consecuencia de una planeación desenfocada desde el comienzo, donde las ideas iniciales no conciben las vías peatonales, los espacios perimetrales adecuados a los grandes proyectos, ni las zonas verdes requeridas por la norma, al descartar al árbol como elemento urbano importante que afecta el 

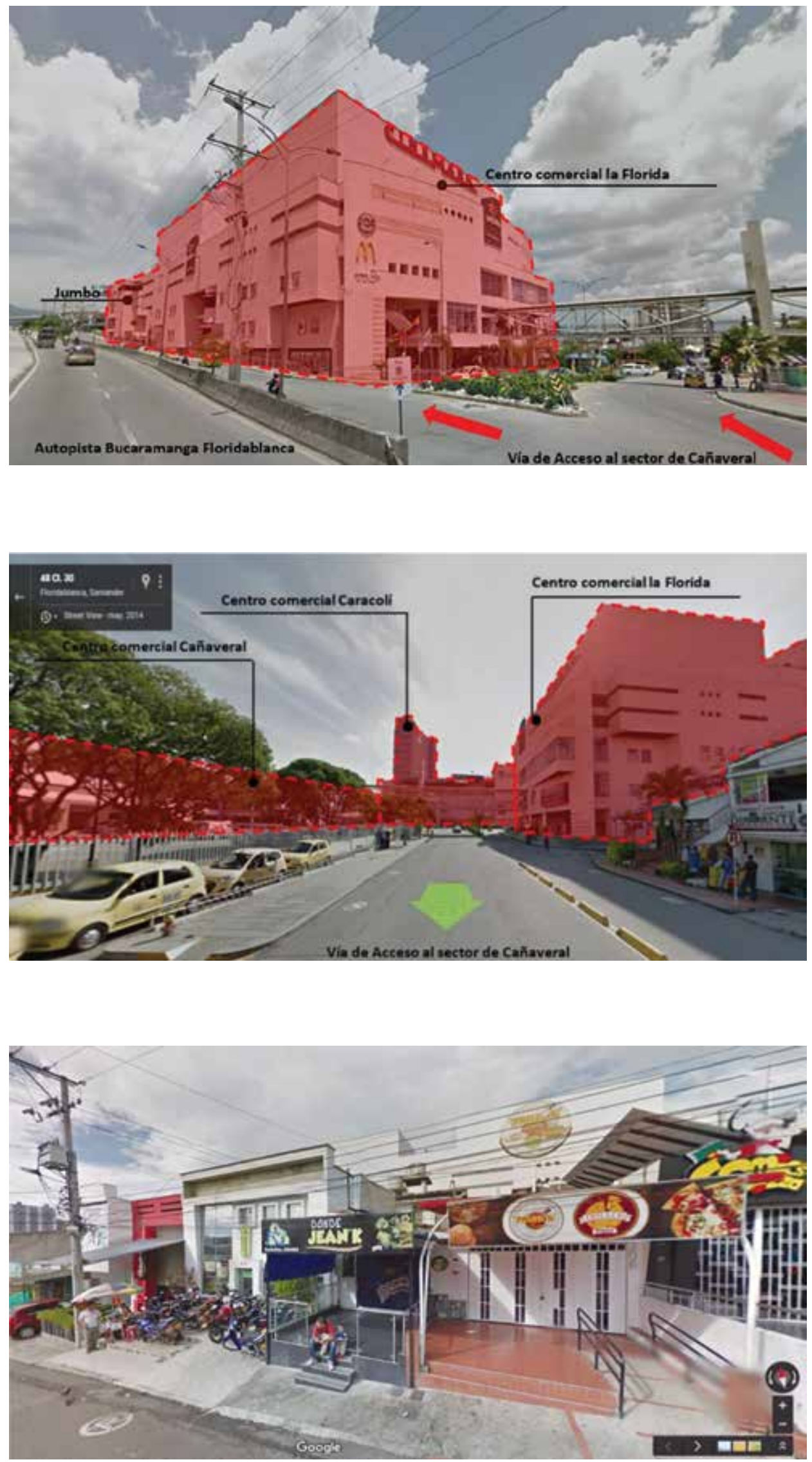

Figura 8. Centro comercial La Florida

Fuente: Imagen de https://www.google.com.co/ maps y editada por el autor (20I6)

Figura 9. Relación centros comerciales existentes en los alrededores del acceso principal al sector de Cañaveral

Fuente: Imagen de https://www.google.com.co/ maps y editada por el autor (20I6).

Figura 10. Fachada modificada para uso comercial en el antiguo sector de vivienda de Cañaveral

Fuente: Imagen de https://www.google.com. co/maps y editada por el autor (2016) 
Figura II. Cambios de uso dentro del sector de Cañaveral

Fuente: Imagen de https://www.google.com. co/maps y editada por el autor (2016)

Figura 12. Andenes y vías vehiculares dentro del sector de Cañaveral

Fuente: Imagen de https://www.google.com co/maps y editada por el autor (2016).

Figura 13. Espacio Público correspondiente a un tramo del sector perimetral del Centro Comercial La Florida

Fuente: Imagen de https://www.google.com co/maps y editada por el autor (2016).
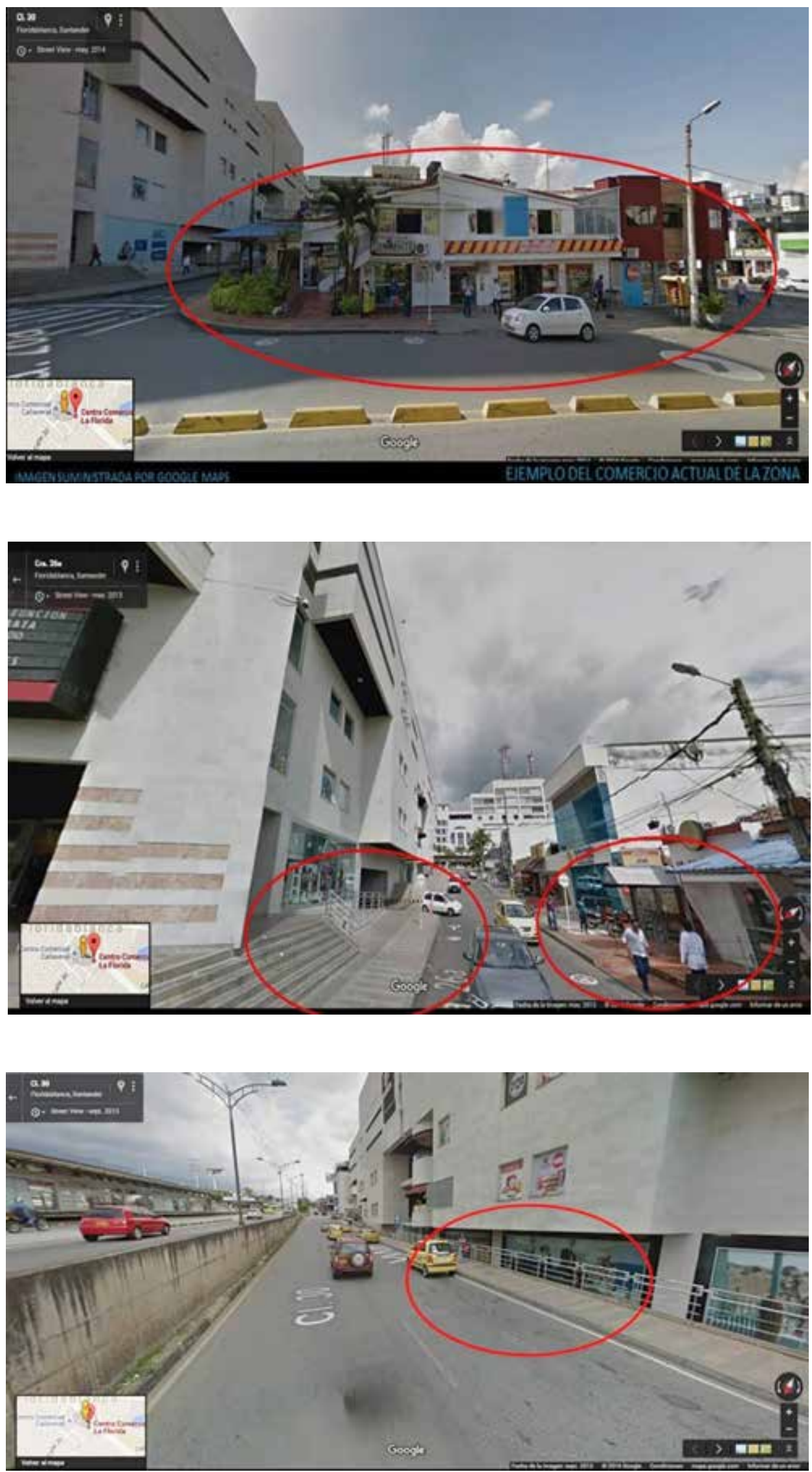

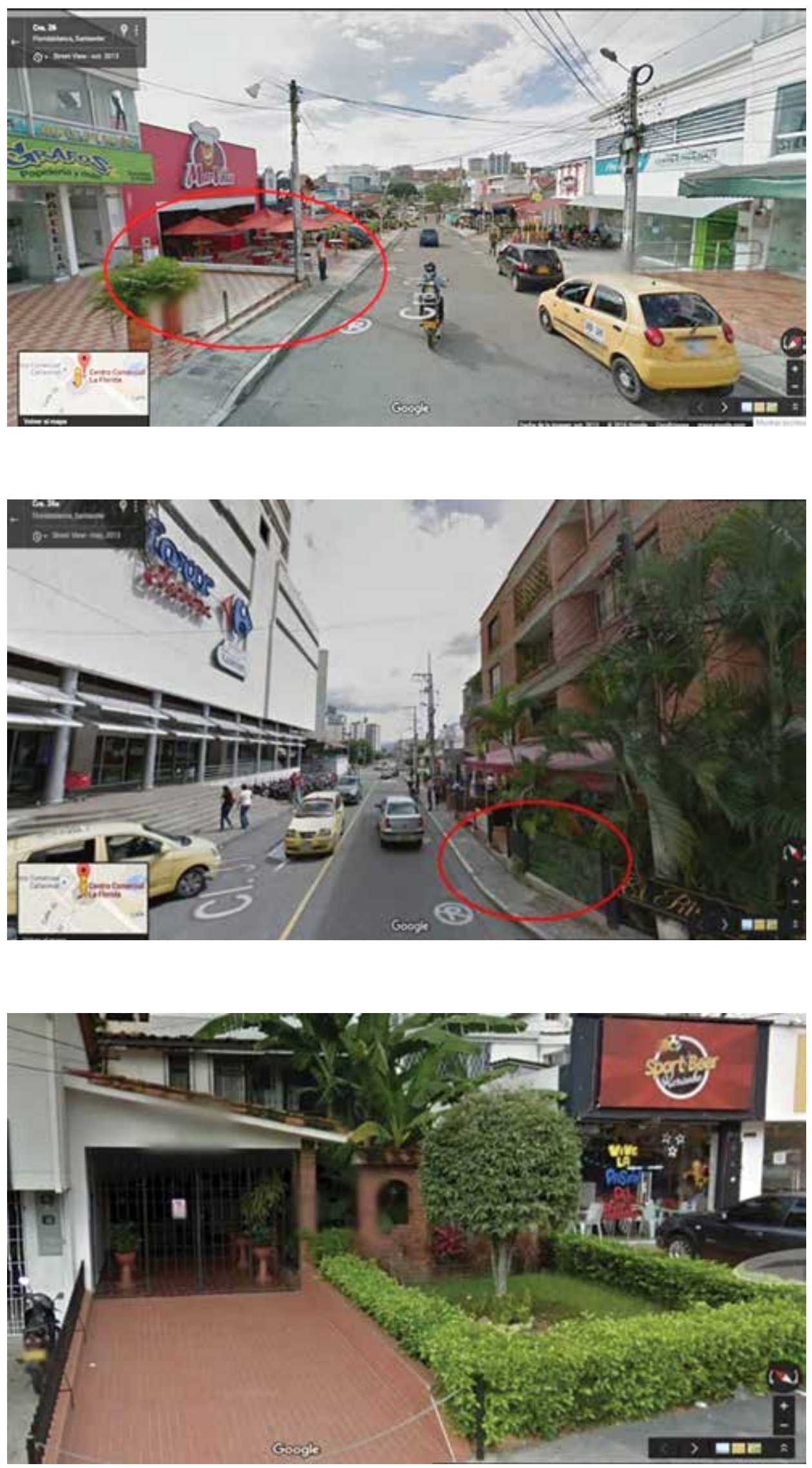

M 79 REVISTA M VOL. 13 ENERO - DICIEMBRE 2016 - FACULTAD DE ARQUITECTURA • UNIVERSIDAD SANTO TOMÁS COLOMBIA
Figura 14. Endurecimiento de las antiguas zonas verdes del sector de Cañaveral

Fuente: Imagen de https://www.google.com co/maps y editada por el autor (2016).

Figura I5. Relación espacio construido - vías (peatonales y vehiculares)

Fuente: Imagen de https://www.google.com co/maps y editada por el autor (2016).
Figura 16. Modelo de vivienda original correspondiente al sector de Cañaveral Fuente: Imagen de https://www.google.com. co/maps y editada por el autor (20I6). 
paisaje y el entorno natural que anteriormente se observaba en el sector de Cañaveral, así como la demanda de nuevas y mejores vías con el fin de aliviar la congestión vehicular. Así mismo, en la figura I 5 se puede observar la falta de equilibrio entre las construcciones y el espacio público, las vías son de un ancho mínimo no apto para el flujo vehicular de la zona, de igual forma se hace evidente el cambio de fachada en la edificación situada sobre el margen derecho, así como un cambio en su altura y por ende en su ocupación.

Aun así, la tipología original de vivienda proyectada para el sector de Cañaveral se mantiene intacta en algunos puntos, como se presenta en la figura 16, donde se observa el antejardín, el árbol como elemento importante dentro de la escena compositiva de la fachada, y la altura de dos pisos. Este tipo corresponde actualmente solo al $2 \%$ de las viviendas del sector, que han perdido su valor arquitectónico por el cambio de uso. Además, dentro de las problemáticas identificadas se encuentra una clara afectación ambiental que va más allá del endurecimiento de las antiguas zonas verdes, donde es importante mencionar la desaparición del llamado Lago de Cañaveral, el cual se encontraba ubicado sobre el costado derecho del conjunto residencial La Pera, y que actualmente es una cancha de baloncesto y un parque urbano.

Finalmente y teniendo en cuenta lo expuesto anteriormente, se hace necesario un replanteamiento del ordenamiento territorial local, vinculándolo al urbanismo experimental como elemento importante en la organización del territorio, donde se invite a repensar el urbanismo desde los conceptos de un ambiente humanizado, además de reorientar los territorios a partir de la visión sustentable, pensada desde lo global para actuar en lo local. Por otra parte, se debe buscar que el sujeto que produce el espacio cultural vivido, conozca la realidad que construye con sus pensamientos y sentimientos, de esta manera, se podría decir que el ambiente humanizado, visto a partir de la experiencia, conduce a captar de manera integral el dinamismo con que se va a transformar la calidad de la vida urbana (Contreras-Lovich, p. 19).

\section{CONCLUSIONES}

- Los planes urbanísticos de Sert y Wiener propuestos para Colombia fueron los primeros ejemplos de aplicación de lineamientos generales para la reorganización y la expansión o crecimiento de la ciudad, propuestas que se realizaron desde la corriente de la arquitectura moderna, las cuales en nuestro país perdieron su rumbo durante su desarrollo.

- Se observó un deterioro en el sector de Cañaveral bastante crítico a nivel de espacio público, manejo de índices de construcción y de ocupación de las nuevas construcciones, desapareciendo las zonas verdes y los árboles sin argumentos claros para sustentar dicha situación.

- Por otro lado, las vías de acceso y las vías internas del sector de Cañaveral no tienen la capacidad para soportar los altos flujos vehiculares que se presentan actualmente, obviando dentro de su diseño el espacio requerido para realizar ampliaciones futuras y el mejoramiento de la infraestructura, teniendo en cuenta la capacidad de transito proyectado para años venideros.

- Así mismo, se evidenció el incremento de lo que se ha denominado la fortificación del sector, en referencia a la aparición de nuevos condominios, o conjuntos cerrados de vivienda, los cuales buscan generar algunos beneficios para sus residentes, como el control de la inseguridad y la misma falta de espacios públicos en la zona que se presentan por otros factores como el de los cambios de uso de suelo. Dichos conjuntos han contribuido al aumento de los índices poblacionales de Cañaveral, así como a la fragmentación del espacio dentro de este importante sector del municipio de Floridablanca.

- De igual forma, se dio prioridad a la expansión de las zonas comerciales en detrimento del espacio público, evidenciado en la construcción de los tres centros comerciales 
mencionados, los cuales generaron un gran impacto social, paisajístico y económico en la zona. El desarrollo desmedido del comercio, pasando por alto las normas establecidas respecto a los cambios de uso de suelo en el sector de Cañaveral, dieron paso a una transformación caótica de la zona estudiada.

- Finalmente, se debe recalcar que en la actualidad la importancia del ordenamiento del territorio debería enfocarse en la visión sustentable de este, donde los diferentes elementos que lo componen sean apoyados por instrumentos de gestión integrales que incluyan la participación de la población, de tal forma que no se afecte la calidad de vida de quienes lo habiten, y proyectando siempre a futuro con responsabilidad social.

\section{REFERENCIAS}

Banco Mundial. (2015). Ciudades de Latinoamérica, entre las más competitivas del mundo. Recuperado de http://www.bancomundial.org/es/news/feature/2015/I2/15/latin-americancities-competitiveness.

Contreras-Lovich, H. (2016). La representación social del espacio público para el diseño y la gestión de territorios sostenibles. Una propuesta teórica-práctica y metodológica para un urbanismo participativo. Revista de Arquitectura, I8(I), 18-34.

Departamento Administrativo Nacional de Estadística - DANE. (2016). Información estratégica. Recuperado de http://www.dane.gov.co/index.php/estadisticas-por-tema/ demografia-y-poblacion

Di Gregorio, R. (2007). II territorio come organizzazione II territorio come organizzazione - Istituto di Ricerca sulla Formazione. Recuperado de http://www.formazioneintervento.it/ amministrazione/rassegna_stampa/stampa_action.php?ACTION=visualizza_file\&cod_allegato $=126$ PDF.

Eslava, C. (20I I). Cañaveral, su evolución en gráficas. Testigo del desarrollo. Recuperado de http://www.gentedecanaveral.com/20 I l/I I/canaveral-su-evolucion-en-graficas/

Eslava, C. (20I5). El 'Ayer' y el 'Hoy' de nuestro sector. Recuperado de http://www. gentedecanaveral.com/2015/09/el-ayer-y-el-hoy-de-nuestro-sector/

Hernández, Y. (2010). El ordenamiento territorial y su construcción social en Colombia: un instrumento para el desarrollo sustentable. Revista colombiana de geografia, 19, 97-109

Palacios, A. (2015). Impacto socio-espacial de la implantación de centros comerciales en Bogotá D.C. Perspectiva geográfica, 20 (2), 319-338. Recuperado de https://dialnet.unirioja. es/descarga/articulo/562696I.pdf

Rodríguez, F., Lozada, I. (2012). Caracterización del sector inmobiliario con actividad comercial y potencial desarrollos en los barrios: Centro Cabecera y Cañaveral del área metropolitana de Bucaramanga. Universidad Industrial de Santander, Bucaramanga, Colombia.

Sánchez, D. (2012). Aproximaciones a los conflictos sociales y propuestas sostenibles de urbanismo y ordenación del territorio en México. Revista de Estudios Sociales, 42, 40-56.

Schnitter, P. (2003). Sert y Wiener en Colombia. La vivienda social en la aplicación del urbanismo moderno. Scripta Nova. Revista Electrónica de Geografía y Ciencias Sociales, 7 (I46) Recuperado de http://www.ub.es/geocrit/sn/sn-I46 (035).htm>

Sert, J. (1942). Can our cities survive An ABC of urban problems, their analysis, their solutions; based on the proposals formulated by the C.I.A.M., International. Internationaux d'architecture modern. Cambridge: Harvard University Press. 